\title{
A vertical wind turbine monitoring system using commercial online digital dashboard
}

\author{
A. K. Ermeey, M. M. Taib, A. R. Nasran, Y. M. Yushafizee
}

Faculty of Electrical Engineering, Universiti Teknologi MARA, Malaysia

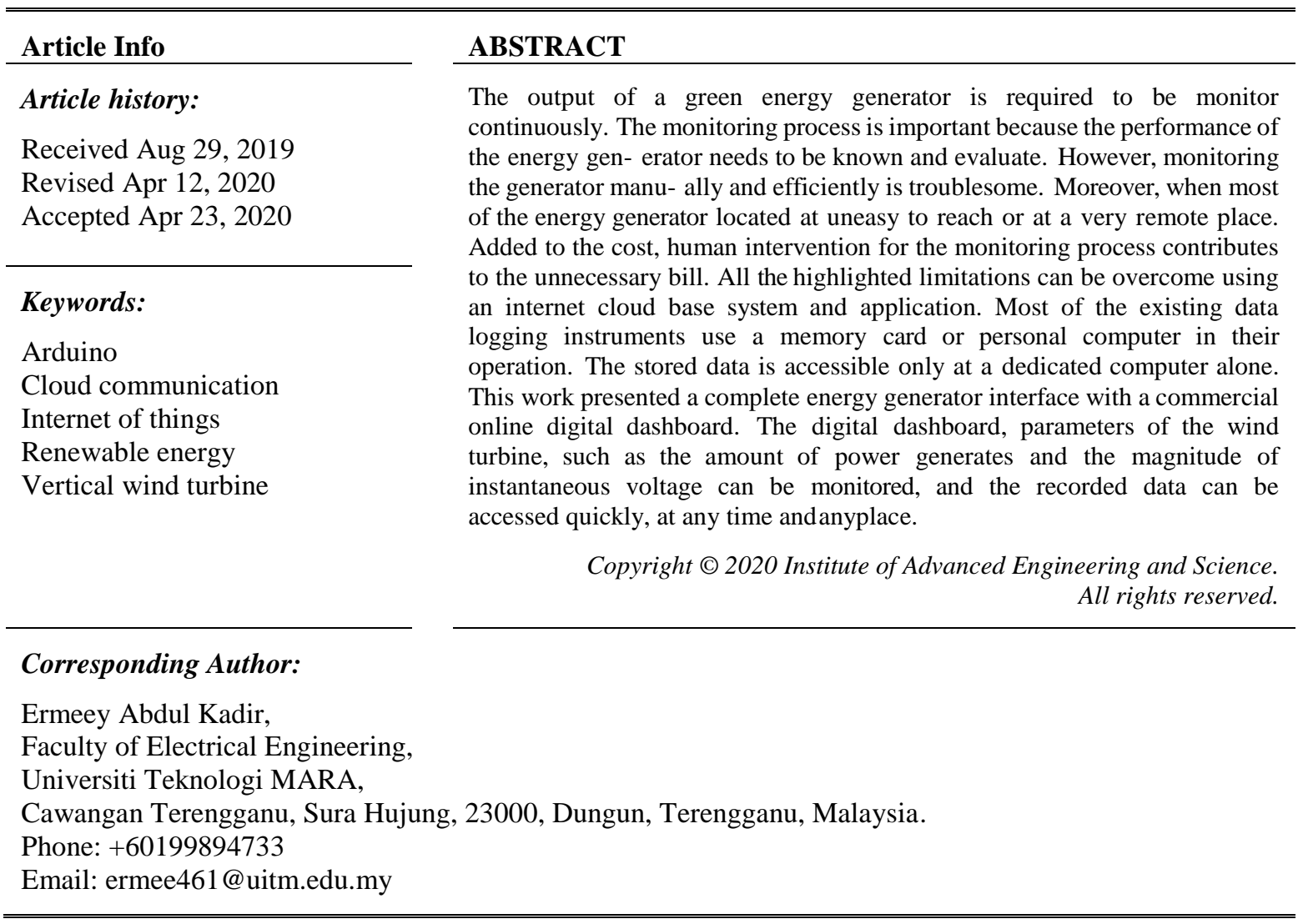

\section{INTRODUCTION}

Green energy generator has been recognized as one of an alternative method to produce electrical energy required for human needs. Energy generated from solar, wind, hydro, geothermal, etc. has been proven can supply electrical energy effectively. Mostly, all these energy farms are in a massive area, remote places, and put at a high platform. Most of the stated green energy source is required to be measured, and the generated data need to be stored and analyzed.

Previous researches have presented a variation of technique and approach as a solution to the problem. The safe and cost-effective design of a wind turbine generator (WTG) grounding system requires accurate modelling of local soil resistivity, mainly when wind turbines are spatially distributed across a wide area with different soil types and features [1]. Here, three locations at an Australian wind farm were modelled based on manually collected measured data obtained from the parameter's instrumentation. An 8 X 8 (64) IoT wind farm platform was built using miniaturized wind turbines with wireless connectivity. The farm was deployed on the south-east coast of Ireland to remotely collect data of a data-driven wind turbine output model and study aerodynamic interactions between turbines within the farm. Each of the 64 turbines simultaneously reported its voltage output measured across a load resistor. An ultrasonic wind sensor equipped with the same internet of thing (IoT) platform have measured the wind speed and wind direction necessary for the offline wind turbine model evaluation. The work emphasizes the potential of using inexpensive wireless, battery-powered, IoT node for remote data collection in preference to a wired solution 
using a data-logger that has limited storage that cannot be remotely accessed [2]. Another work has proposed a low-cost Wind turbine monitoring and control system with a data logging facility. Parameters of the wind plant-like amount of power generation, the magnitude of instantaneous voltage and currents, level of vibration, turbine speed, humidity, and temperature have been monitored periodically. In the proposed system, the turbine control was adopted based on the turbine vibration level, and IoT was implemented by using Raspberry Pi and Arduino microcontrollers [3]. A software-defined quadcopter-6 wheeled industrial IoT (SDQ-6WI) architecture based on a developed quadcopter system to collect wind speed data from a mobile IoT vehicle base station that was based on a developed open flow (DOV) protocol operation has been proposed in [4]. The mobile ground vehicle act as a wind speed measurement system that travels on a given set of waypoints to measure the best optimal wind speed quality and send the collected information to the quadcopter-based SDN controller then to the cloud for further processing. However, the proposed system only best for a single controller and used high power consumption, especially at the data collection process.

An improved one-power-point (OPP) maximum power point tracking (MPPT) algorithm for wind energy conversion system (WECS) to overcome the problems of the conventional OPP MPPT algorithm, requiring pre-knowledge of system parameters, and non-uniqueness of the optimum curve has been presented in [5]. The proposed algorithm neither requires knowledge of system parameters nor mechanical sensors. Besides, it improves the efficiency of the WECS. An experiment has been carried out to demonstrate the validity of the proposed MPPT algorithm. The experimental results compare well with system simulation results.

The proposed system suit best for a wind condition of 6 to $9(\mathrm{~m} / \mathrm{s})$. Utilizing sea breeze to generate electric power by using offshore windmills has been proposed in [6]. In this research, the challenges in offshore wind turbine installations were investigated and analyzed. Here, the data collection and monitoring are done by using unconventional using Texas Instrument CC3200 LaunchPad XL, which works on the IoT concept. However, the research focuses explicitly on the detection and monitoring of plant parameters using the Texas Instrument IoT module. Due to the movement of vehicles, especially on a highway, wind energy is enormously produced and unused. Therefore, we can make use of the energy to produce power and to overcome some problems with electricity. Research has proposed to put a windmill or wind turbines at the mid of the highway. The reason is due to the movement of vehicles on both sides. The generated power then used for nearby streetlights. All these parameters are controlled and monitored through IoT from the base station.

As highlighted in the previous paragraph, most of the reported research has adapted various wind turbine, and the research on this field keeps expanding [7-13]. Most of the highlighted research also have tried to adopt IoT in their proposed system [14-20]. Furthermore, extended the proposed data collection through internet and Cloud platform [21-26]. Hence, there is still an area of improvement. In this research, an online monitoring system for a vertical wind turbine using an online digital dashboard is propose for an energy generator located at a low Wi-Fi signal coverage area. The proposed system position at a meter above the ground. The measured data is record and store automatically through a cloud base system. The performance of the wind turbine is monitor and through an online dashboard from a mobile application.

\section{RESEARCH METHODOLOGY}

In this section, the proposed system is elaborated by using an electrical circuit. The explanation is divided into two phases. In the first phase, the vertical wind turbine system is model and represents in a schematic diagram. In the second phase, an explanation of the microcontroller operation is discussed.

\subsection{System modelling}

The proposed energy generator with a peripheral interconnection circuit is model and analyze. The proposed system is represented in terms of electrical component and illustrates in Figure 1(a). As simulation purposes the circuit shown in Figure 1(a), the Vertical Wind Turbine is assumed as a 3-phase $24 \mathrm{~V}$ alternating circuit (AC) signal source. The 3-phase signal from the generator is then converted to direct current (DC) signal through a rectifier. The input of an Arduino micro-controller is through a voltage divider circuit. The voltage output then is level up by a Boost converter. A MOSFET is used to prevent reverse polarity at the storage device. A Capacitor, $C_{1}$, is used to filter out the AC signal, and the generated energy is store in a $12 \mathrm{~V}$ Deep Cycle Battery. For every single phase, the proposed system can be represented in a schematic circuit, as depicted in Figure 1(b). For every positive and negative cycle of the input signal, $D_{1}$ and $D_{2}$ are alternatively switched $\mathrm{ON}$ and $\mathrm{OFF}$, respectively. The voltage across the storage device is represented by;

$$
V_{\text {out }}=I_{L} Z_{2}
$$


where $I_{l}$ is the current through $1 \mathrm{H}$ inductor and $Z_{2}$ is the impedance summation the circuit components represent as

$$
Z_{2}=j \omega_{L}+R_{L} /\left(\omega_{C} R_{L}+1\right)
$$

where $\omega=2 . \pi . f$. The parameter $f$ is standing for the blade rotation in-unit, Hertz. As shown in (1) and (2), the output voltage is determined by the value of current through inductor $L_{1}$ and $f$, respectively. Figure 2(a) depicted an output voltage of the DC generator. The voltage output steadily increased as the blade rotation speed, $f$ increased from 0 to $50 \mathrm{~Hz}$. By referring to the mathematical analysis in (1) and (2), it has been found that the turbine speed and the generator rated output current are the important parameters in producing a high output voltage for charging up the storage device.

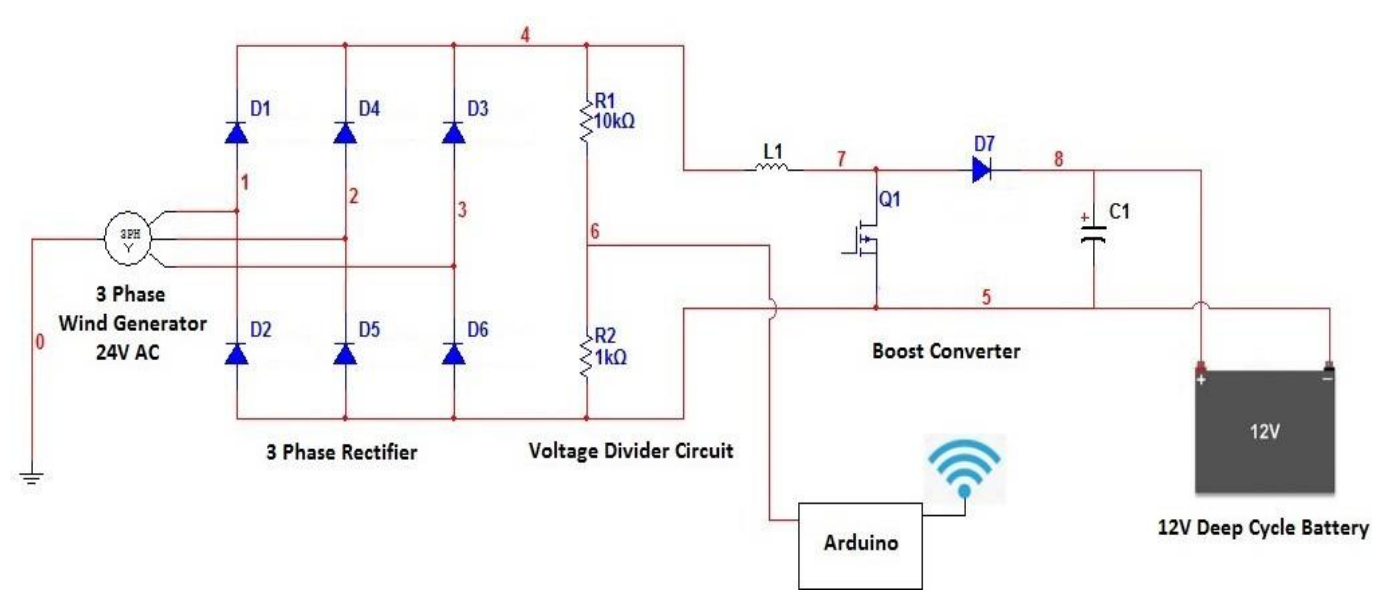

(a)

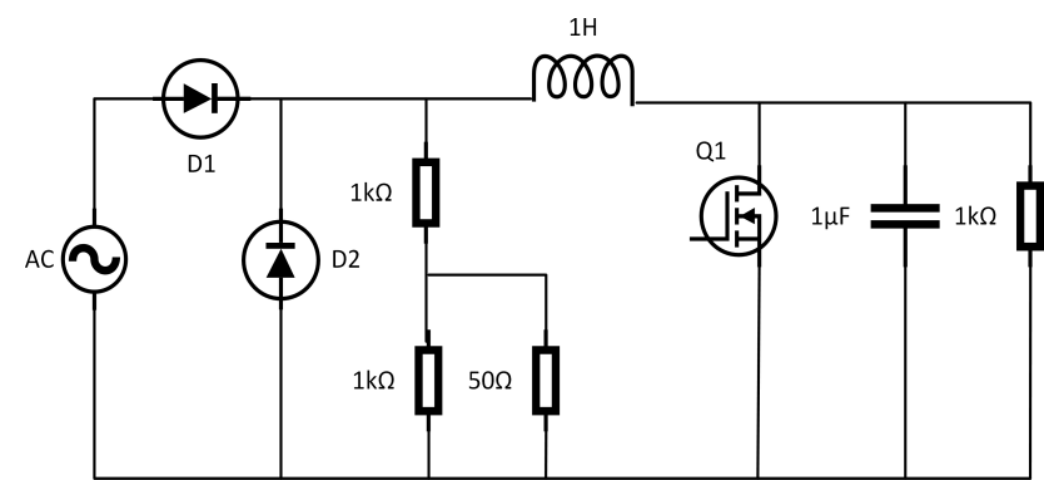

(b)

Figure 1. (a) The proposed system, (b) The schematic circuit of the converter circuit

\subsection{IoT-based wind turbine monitoring system}

The analysis of the proposed system discussed in the earlier section shows that three parameters are required to be monitored. The parameters are used to evaluate the performance of the wind turbine system. For the system evaluation, those three parameters are collected using a data collection system, and an Arduino microcontroller is used for that purpose

A block diagram of the propose monitoring system in Figure 2(b) illustrates the system arrangement. The monitoring system is divided into five distinct functions, which are sensor node, repeater node, gateway node, internet, and the system application. The sensor node is consisting of a wind turbine, voltage sensor, Arduino microcontroller, and XBee transceiver. Here is where most of the hardware for the data collection system is be distributes. Data collected from multiple sensors are sent to the internet via repeater and gateway node. At the internet site, an application known as Bylink is used as the graphical user interface where stakeholders can fetch the data obtained from sensors for their evaluation purposes. 


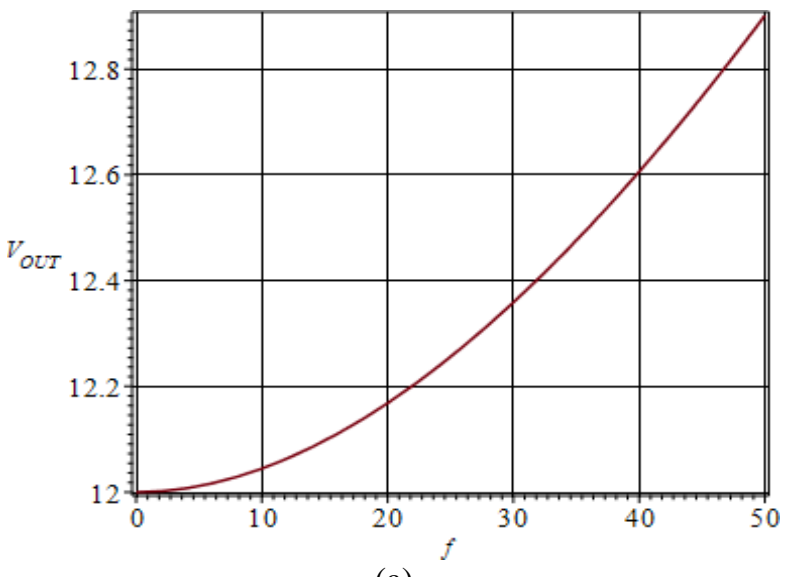

(a)

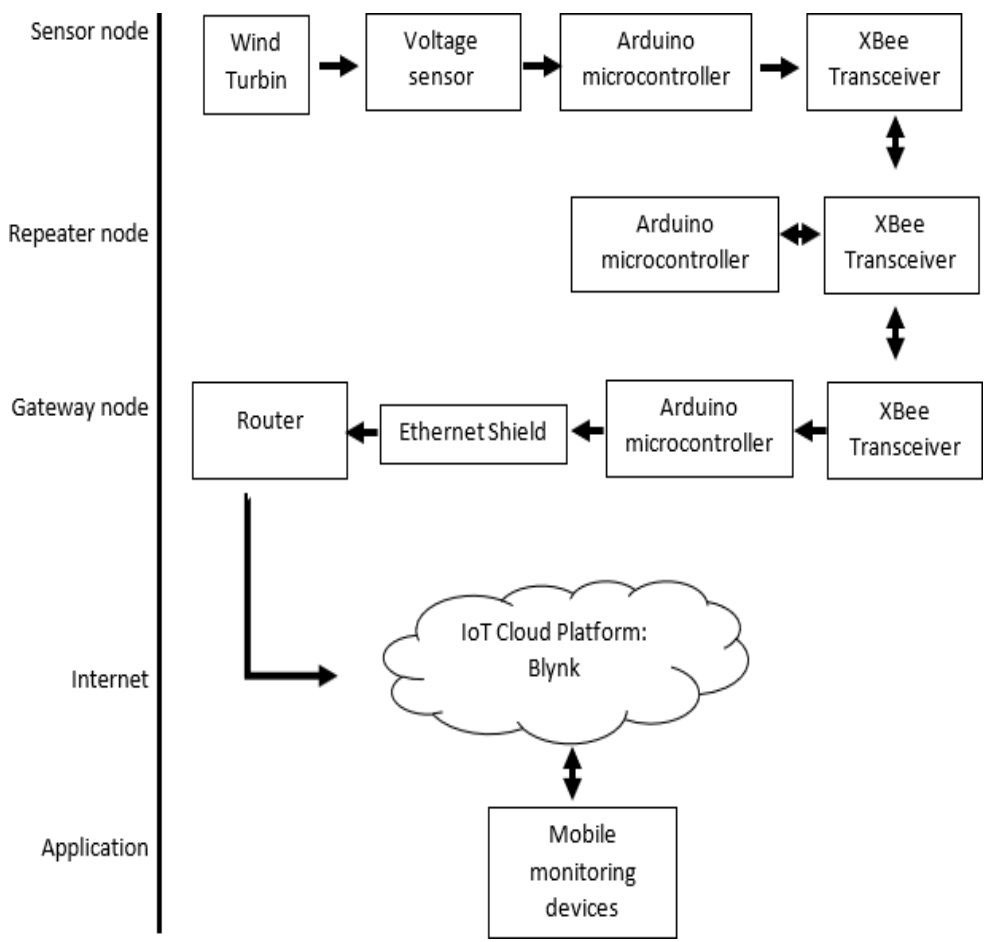

(b)

Figure 2. (a) The proposed system output voltage, (b) the block diagram of the data collection system

\subsection{Online digital dashboard operation}

The operation of the online digital dashboard and communication components are simplified using a flowchart. The flowchart represents the operation of the sensor, repeater, and gateway nodes. Figure 2(b) explains that the process of sending data starts from a sensor node up to the cloud storage via an internet gateway. As shown in the figure, for each node, a direct data fetching step is selected to prevent the system from halt during operation.

\subsection{Pseudocode and micro-controller codes}

The Arduino microcontroller code arrangement is straightforward programming for easy error detection. The code used for the data collection and monitoring are downloaded into the micro-controller, and the program is running continuously. The Pseudocodes for the microcontroller programming are listed in Figure 3. The programming code for the microcontroller is for sensing, recording the output voltage, repeating the earlier process, and sending the data value to the internet gateway. The programming of the microcontroller is highlighted in Figure 4. 


\begin{tabular}{|l|l|l|}
\hline Sensor node: & Repeater: & Gateway node: \\
Start & Start & Start \\
Loop forever: & Loop forever: & Establish internet \\
Get analog reading from A0 & Wait for serial data to arrive & connection \\
analog pin & Redirect serial data to & Set up unique auth token \\
Perform 12bit analog to & destination address upon & generated from blynk app \\
digital conversion & arrival & Loop forever: \\
Transmit data through & Repeat loop & Wait for serial data to arrive \\
serialprint() & End & Process char to integer \\
Wait 1 second & & conversion upon receiving \\
Repeat loop & data packet \\
End & Convert data to voltage form \\
& & Push data to blynk server \\
& & Repeat loop \\
& & End \\
& & \\
& &
\end{tabular}

Figure 3. The pseudocodes of three different nodes

\begin{tabular}{|c|c|c|}
\hline 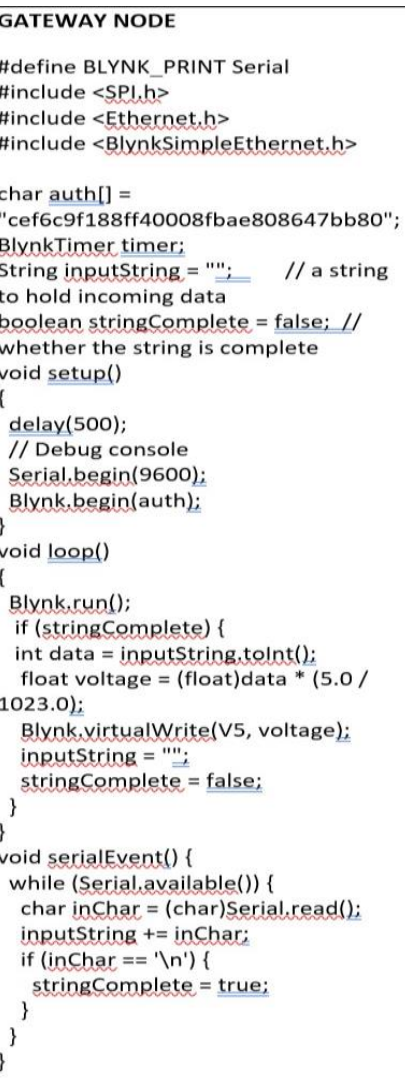 & $\begin{array}{l}\text { SENSOR NODE } \\
\text { void setup() \{ } \\
\text { Serial begin(9600): } \\
\} \text { void loop() \{ } \\
\text { // Wait a few seconds } \\
\text { between measurements. } \\
\text { delay(1000); } \\
\text { int sensorValue = } \\
\text { analogRead(AO): } \\
\text { Serial println(sensorValue): } \\
\}\end{array}$ & 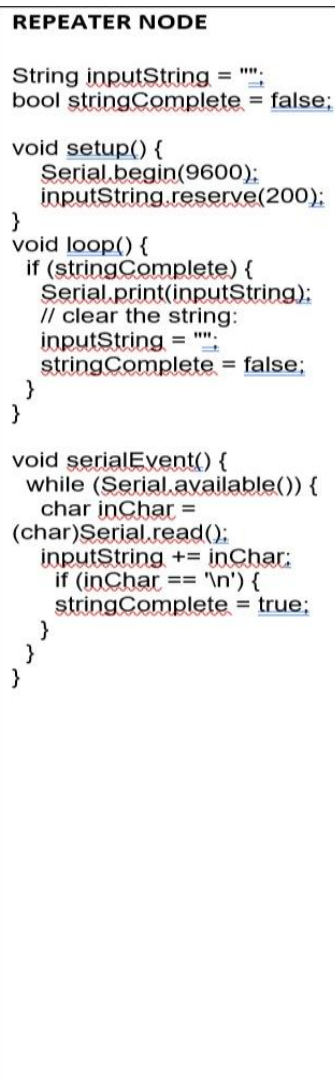 \\
\hline
\end{tabular}

Figure 4. The Arduino microcontroller programming code

\section{RESULT AND ANALYSIS}

In this section, the performance of the system arrangement is demonstrated and explain. A real setup of energy harvester complete with converter, microcontroller, and storage module is installed at a selected site. As depicts in Figure 5(a), a vertical wind turbine uses to transform the free energy from the surrounding wind is installed on top of a building. The turbine blade of the vertical wind turbine is connected to a $300 \mathrm{~W}$ direct current (DC) generator through one metal shaft. The output of the DC generator is connected to a converter circuit, as highlights in Figure 5(b). The operation of the converter circuit is explained in the earlier section. A $300 \mathrm{~W}$ AC-DC inverter is used to converts the generated energy and as a power supply for the Arduino microcontroller. The converted DC signal is also transferred to the storage battery accordingly. The performance of the energy generator can be monitored by using an android app and display through an online digital dashboard. Transferring the data could be done since the Arduino microcontroller is connected through the internet. Commercial apps use for the purpose is known as Bylnk, and the example of 
the recorded data is shown in Figure 6(a). As depicted in the figure, using the app, live data can be display, and three different parameters can be recorded, which are the voltage, temperature, and humidity of the proposed system. The $\mathrm{X}$-axis displays the time of the data taken and stored in the cloud storage.

For further verification of the proposed system, the performance of the energy generator and monitoring system is programmed to record data for one month. The recorded data is reported in Figure 6(b). As seen from the figure, for every single day, the vertical wind turbine is actively generating energy. The generated energy is stored in the storage device, which is a set of batteries. The amount of energy transferred to the storage device can also be calculated, and the value is reported in Figure 6(c).

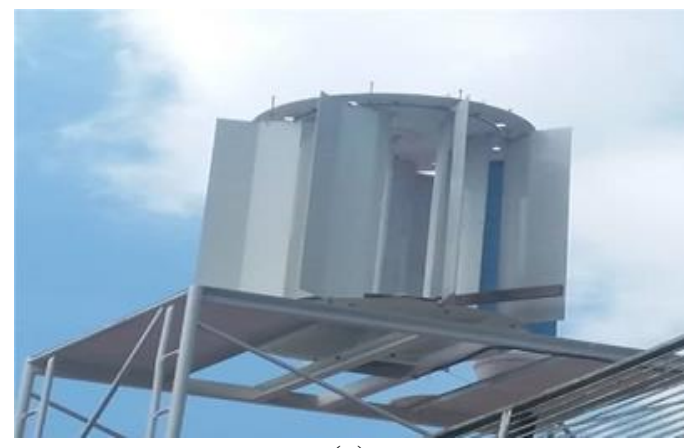

(a)

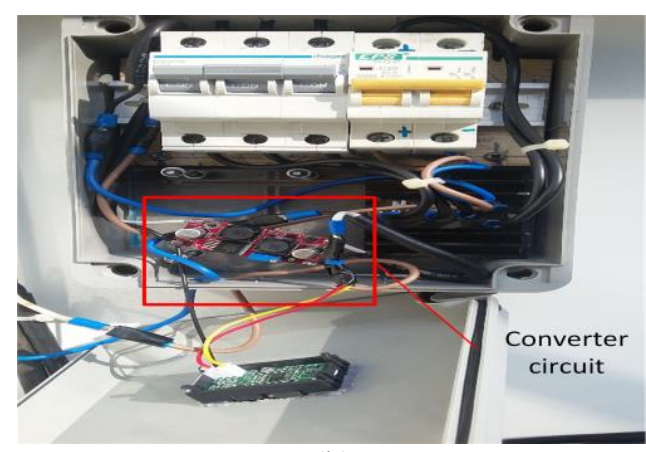

(b)

Figure 5. (a) The vertical wind turbine, (b) The converter circuit

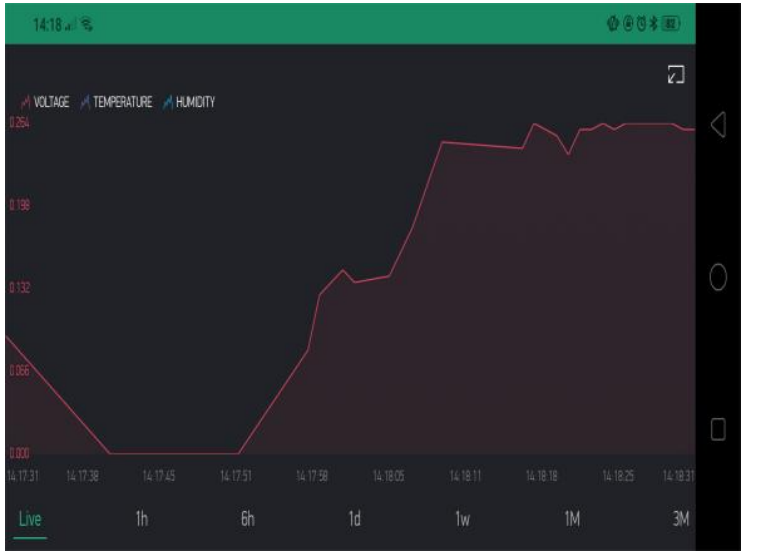

(a)

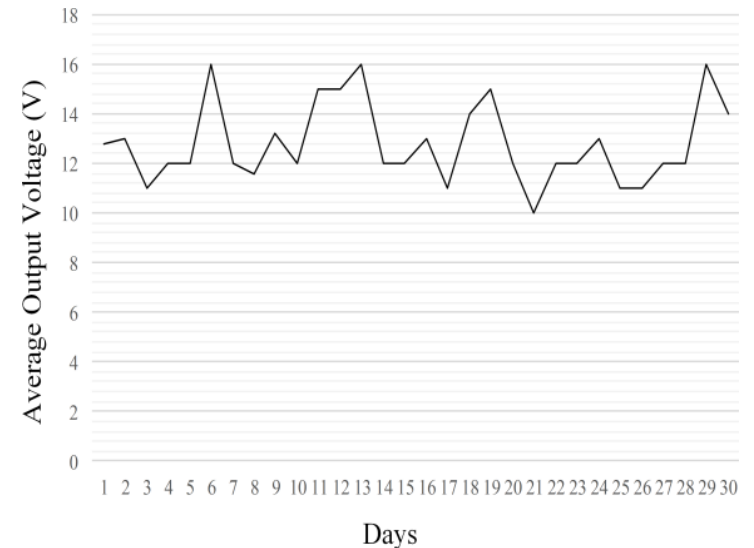

(b)

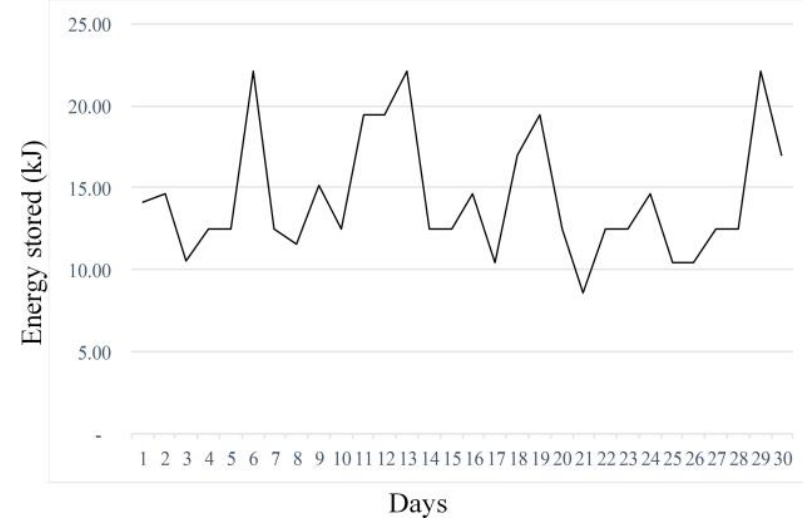

(c)

Figure 6. (a) The Bylink dashboard display, (b) A monthly output voltage of the proposed system,

(c) Calculated energy transferred to the storage device in Joule 


\section{CONCLUSION AND DISCUSSION}

This research is proposed to ease the process of monitoring and evaluating the performance of the renewable energy generation system. The proposed system arrangement is using basic electronics components, an Arduino microcontroller, a few sensors, and a free cloud storage facility which is already available in the android application store. The arrangement of the proposed system is modelled, and the expected output voltage is estimated. It is shown that the value of the estimated and the actual result is in proximity. A vertical wind turbine with a capacity of $300 \mathrm{~W}$ is installed at a selected site, and the performance of the energy generator is being monitored and evaluated. From the actual experiment, the average output voltage is $12.5 \mathrm{~V}$. Daily, an average of $15 \mathrm{~kJ}$ is stored in the storage device. The values are recorded, and an online dashboard is used as the user interface. The proposed research proves that the system is suitable to fulfil the objective, and the arrangement of components for monitoring the renewable energy generation system works accordingly.

\section{ACKNOWLEDGEMENT}

This research is a collaboration between Universiti Teknologi MARA Cawangan Terengganu and Steelcon Energy Sdn Bhd under Memorandum of Understanding (2016).

\section{REFERENCES}

[1] R. D. Goud, T. Auditore, R. Rayudu and C. P. Moore, "Frequency Domain Analysis of a Wind Turbine Generator Earthing System for Lightning Discharge Currents," in IEEE Access, vol. 7, pp. 60501- 60512, 2019.

[2] B. Srbinovski, G. Conte, A. P. Morrison, P. Leahy and E. Popovici, "ECO: An IoT platform for wireless data collection, energy control and optimization of a miniaturized wind turbine cluster: Power analysis and battery life estimation of IoT platform," 2017 IEEE International Conference on Industrial Technology (ICIT), Toronto, ON, pp. 412-417, 2017.

[3] D. Kalyanraj, S. L. Prakash and S. Sabareswar, "Wind turbine monitoring and control systems using Internet of Things," 201621 st Century Energy Needs - Materials, Systems and Applications (ICTF- CEN), Kharagpur, pp. 1-4, 2016.

[4] A. K. Al Mhdawi and H. S. Al-Raweshidy, "SDQ-6WI: Software-Defined Quadcopter-Six Wheeled IoT Sensor Architecture for Future Wind Turbine Placement," in IEEE Access, vol. 6, pp. 53426-53437, 2018.

[5] M. A. Abdullah, T. Al-Hadhrami, C. W. Tan and A. H. Yatim, "Towards Green Energy for Smart Cities: Particle Swarm Optimization Based MPPT Approach," in IEEE Access, vol. 6, pp. 58427-58438, 2018.

[6] N. P. G. Bhavani, P. Vaishnavi and K. Sujatha, "Off-shore wind power as a pillar of energy transmission using IOT (OSWPETIOT)," 2017 International Conference on Energy, Communication, Data Analytics and Soft Computing (ICECDS), Chennai, pp. 2494-2499, 2017.

[7] M. S. Pramod, P. N. Naveen, N. R. Chaithra, K. Ranjith and G. H. S. Vikas, "Monitoring of high- way wind power parameter and controlling highway light through IoT," 2017 2nd IEEE International Conference on Recent Trends in Electronics, Information Communication Technology (RTEICT), Bangalore, pp. 1750-1753, 2017.

[8] Albuquerque, I. M. and F. F. S. Matos, "A Characterization of Vertical Axis Wind Turbines," IEEE Latin America Transactions, vol. 14, no. 10, pp. 4255-4260, 2016.

[9] Fathabadi, H., "Novel Maximum Electrical and Mechanical Power Tracking Controllers for Wind Energy Conversion Systems," IEEE Journal of Emerging and Selected Topics in Power Electronics, vol. 5, no. 4, pp. 1739-17452017.

[10] Lee, D. G., et al., "Maintenance Robot for 5-MW Offshore Wind Turbines and its Control," IEEE/ASME Transactions on Mechatronics, vol. 21, no. 5, pp. 2272-2283, 2016.

[11] Mirecki, A., et al., "Architecture Complexity and Energy Efficiency of Small Wind Turbines," IEEE Transactions on Industrial Electronics, vol. 54, no. 1, pp. 660-670, 2007.

[12] Parker, M. A., et al., "Comparison of power electronics lifetime between vertical- and horizontal-axis wind turbines," IET Renewable Power Generation, vol. 10, no. 5, pp. 679-686, 2016.

[13] Preen, R. J. and L. Bull, "Toward the Coevolution of Novel Vertical-Axis Wind Turbines," IEEE Transactions on Evolutionary Computation, vol. 19, no. 2, pp. 284-294, 2015.

[14] Stannard, N. and J. R. Bumby, "Performance aspects of mains connected small-scale wind turbines," IET Generation, Transmission Distribution, vol. 1, no. 2, pp. 348-356, 2007.

[15] Templin, R. J. and R. S. Rangi, "Vertical-axis wind turbine development in Canada," IEE Proceedings A - Physical Science, Measurement and Instrumentation, Management and Education-Reviews, vol. 130, no. 9, pp. 555-561, 1983.

[16] Fadil, J., et al., "Performance comparison of vertical axis and horizontal axis wind turbines to get optimum power output," 2017 15th International Conference on Quality in Research (QiR): International Symposium on Electrical and Computer Engineering, pp. 429-433, 2017.

[17] Khan, S. A. and K. V. S. Rao, "Relevance of power from Small Wind Turbines: A case study for torque - speed characteristics of Small Vertical Axis Wind Turbine for Kota region of Rajasthan," 2016 Biennial International Conference on Power and Energy Systems: Towards Sustainable Energy (PESTSE), 2016. 
[18] Nagare, P., et al., "Vertical axis wind turbine," 2015 International Conference on Technologies for Sustainable Development (ICTSD), Mumbai, 2015.

[19] Srivastava, A., et al., "Utilization of wind energy from railways using vertical axis wind turbine," 2015 International Conference on Energy Economics and Environment (ICEEE), 2015.

[20] Dunlong, L., et al., "Installation height analysis of $\Phi$-type vertical axis wind turbine on the flat building," 2016 IEEE International Conference on Power and Renewable Energy (ICPRE), pp. 669-674, 2016.

[21] Choi, C., et al., "LoRa based renewable energy monitoring system with open IoT platform," 2018 International Conference on Electronics, Information, and Communication (ICEIC), 2018.

[22] Ku, T., et al., "Hybrid Energy Management System for Community Energy System Facilities," 2017 IEEE International Conference on Smart Cloud (SmartCloud), pp. 98-102, 2017.

[23] Ku, T., et al., "Self-learning mechanism for prediction of energy consumption and generation," 2018 20th International Conference on Advanced Communication Technology (ICACT), pp. 359-362, 2018.

[24] Raaju, V. A., et al., "IOT Based Smart Garbage Monitoring System Using ZigBee," 2019 IEEE International Conference on System, Computation, Automation and Networking (ICSCAN), 2019.

[25] Santora, M. and R. Oare, "Modular low-power, low-noise, low-cost, wirelessly networked data acquisition system," OCEANS 2016 MTS/IEEE Monterey, 2016.

[26] Zedak, C., et al., "A proposed secure remote data acquisition architecture of photovoltaic systems based on the Internet of Things," 2018 6th International Conference on Multimedia Computing and Systems (ICMCS), 2018.

\section{BIOGRAPHIES OF AUTHORS}

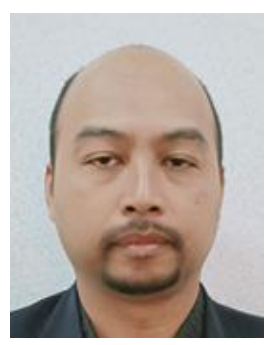

Ermeey Abd Kadir is a Doctoral degree holder from the school of Electrical and Computer Engineering from The University of Auckland (2016). His researches are in fields of electronics, communication engineering, renewable energy, and energy harvesting system. Recently, the system's application on a low power energy harvesting system has been tackled. He is affiliated with IEEE as a student member. In IET and other scientific publications, he has served as an invited reviewer.

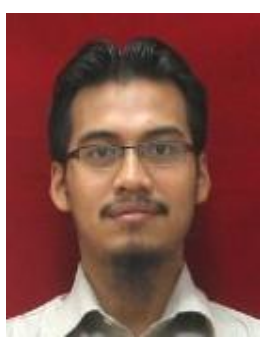

Mohamad Taib Miskon is a lecturer in the Faculty of Electrical Engineering UiTM. Currently, he is pursuing a PhD degree in the control system in UiTM. His research interests are dynamic modelling and control, the internet of things, and embedded systems.

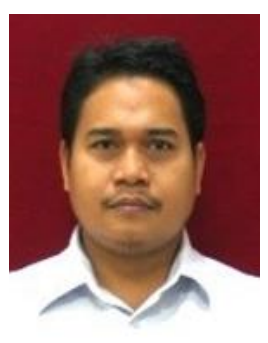

Nasran Abd Rashid received his Diploma in Electronics Engineering. Currently, he is an assistant lecturer in the Faculty Electrical and Electronics Engineering, UiTM Cawan- gan Terengganu.

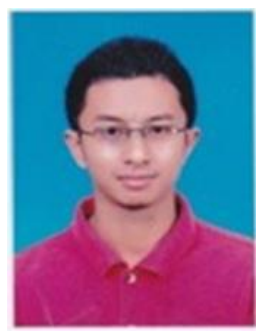

Mat Yushafizee Mat Yunus received his Diploma in Electrical Power from Universiti Teknologi Malaysia. Currently, he is an assistant lecturer in the Faculty Electrical and Electronics Engineering, UiTM Cawangan Terengganu. 